\title{
Exploring the Psychological Risk Factors in Children with Epilepsy
}

\author{
Mimoza Maloku Kuqi \\ University Clinical Center of Kosovo, Pediatric Clinic, Pristina, KOSOVO \\ Hazir Elshani \\ Office for Psychological Issues, Municipal Directorate of Education, ALBANIA
}

Eglantina Dervishi

University of Tirana, Faculty of Social Sciences, ALBANIA

Department of Psychology and Pedagogy

Silva Ibrahimi

Albanian University, Department of Psychology, Tirana, ALBANIA

Received: 7 July 2020 - Accepted: 18 November 2020 - Published Online: 9 December 2020

\section{Abstract}

There are many factors that aggravate the clinical picture of children diagnosed with epilepsy. Through this study we will explore risk factors related to disease characteristics, cognitive impairments, intelligence and behavioral problems in children with epilepsy. Methods: Based on the medical data of children diagnosed with epilepsy being treated at the Pediatric Neurology Unit, University Hospital of Pristina, and the "Hope" Psychological Outpatient Center in Kosovo, about 100 epileptic children, 55 female and 45 male, aged between 6 and 11 years of school age were administered the Montreal Cognitive Assessment scale (MoCA), Raven's Standard Progressive Matrices (IQ), and Child Behavior Checklist (CBCL) tests. Results: Children participating in the study reveals a predomination of the generalized epilepsy, which continue to be treated with anti-epileptics for more than 3 years. From them $67 \%$ did not show the presence of another co-neurological deficit. Neurological tests show evidences of moderate EEG changes in some children and MRI registrations in $65 \%$ of children are unchanged and continue to be treated with 1 or 2 antiepileptic drugs for being under control. Intelligence, cognitive and behavioral problems in cases where they were associated with a number of neuropsychological characteristics increase the risk of a disease aggravation and compromise their overall development. Discussion: We can imply that based on the severity of these concomitant factors of the epileptic conditions, they will constitute a high-risk factor for cognitive problems, low intelligence and the emergence of a number of internalizing and externalizing problems of the child with epilepsy. Conclusions: As a risk factor that increases the level of difficulty of epileptic children in some contexts, including general functioning, school, family and social context, the presence of neurobiological and neuropsychological factors such as issues in internalizing and externalizing behaviors, problems in the cognitive field and the IQ are seen, which is also expected to affect the overall development of children's quality of life.

Keywords: Epilepsy, children, cognitive impairments, general intelligence, behavioral problems, EEG, MRI.

(C) Authors. Terms and conditions of Creative Commons Attribution 4.0 International (CC BY 4.0) apply. Correspondence: Eglantina Dervishi, University of Tirana, Department of Psychology and Pedagogy, Faculty of Social Science, Tirana, ALBANIA. E-mail: egladervishi@yahoo.com. 


\section{Introduction}

Epilepsy is a common neurological disorder in which abnormal electrical discharges from the brain cause recurrent seizures (Paudel, Shaikh, Chakraborti, Kumari \& Aledo-Serrano et al., 2018). Both types of epileptic seizures refer to partial seizures that begin in an area of the brain and generalized seizures that begin in both cerebral hemispheres simultaneously. A study by Reddy and colleagues (Reddy, Younus, Sridhar \& Reddy, 2019) found that epilepsy as one of the most complex brain disorders was associated with spontaneous damage as a result of abnormal electrical discharge in the brain and that about $40 \%$ of children diagnosed with epilepsy appear to have lesions that cannot be treated with antiepileptic drugs. In cases when generalized and partialtype epilepsy are associated with symptoms of synaptic failure (Joy \& Fields, 2019), neurological damage, or manifestation characterized by a hyperexcitability of indefinite duration (Hirosawa, Kikuchi, Fukai, Hino \& Kitamura et al., 2018), it may lead to a clinical manifestation of the chronic stage (Kynast, Lampe, Luck, Frisch \& Arelin et al., 2018). According to Reddy the variety of antiepileptic drugs, however, does not help a part of epileptic patients (Izadi, Ondek, Schedlbauer, Keselman, Shahlaie \& Gurkoff, 2018) who present a form of epilepsy which fails to be fully traced in its clinical symptomatology based on the type of damage it causes (Reilly, Atkinson, Memon, Jones \& Dabydeen et al., 2018) and the area in which it lies in the brain (Jones, Asato, Brown, Doss \& Felton et al., 2020; Burke, Naseh, Rodriguez, Burgess \& Loewenstein, 2019; Noebels, 2015). In most cases what pharmacological treatments do (Cacabelos, 2020; Mollon, Mathias, Knowles, Rodrigue \& Koenis et al., 2020; Williams, 2020) is the symptomatic treatment of the concerns of the epileptic patient, who is only able to control the severity of the injury but gives little opportunity to keep the disease under control (Holmes, 2014).

Cognitive impairments (Wang, Chen, Liu, Lin \& Huang, 2020) are typically associated with epileptic seizures with apparent impairment (Wang, Liu, Liu, Zhang \& Wang et al., 2020) and frequent seizures (Hessen, Alfstad, Torgersen \& Lossius, 2018). But not in all cases epilepsy is associated with cognitive impairments (Hermann, Loring \& Wilson, 2017; Zhou, Chen, Peng \& Ouyang, 2016; Galanopoulou, \& Moshé, 2015). However, there are some conditions that tend to worsen the clinical picture of children diagnosed with epilepsy and compromise not only the course of treatment during the course of the disease (Ravizza, Onat, Brooks-Kayal, Depaulis \& Galanopoulou et al., 2017) but also to be the cause of children struggle with a series of difficulties throughout development stages (Abstracts from the $51^{\text {st }}$ European Society of Human Genetics Conference: Posters, 2019) and slow down life in young patients (E-Poster Viewing, 2019). Cognitive impairments are seen as a risk factor for epilepsy with an early onset and long-term consequences for brain development (E-Poster Viewing, 2019; Makale, McDonald, HattangadiGluth \& Kesari, 2017; Jacobs, Willment \& Sarkis, 2019; Greenberg \& Subaran, 2011; Brooks-Kayal, Bath, Berg, Galanopoulou \& Holmes et al., 2013) especially due to the negative effects that result in the neurodevelopmental (Perry, Lacritz, Roebuck-Spencer, Silver \& Denney et al., 2018) and psychosocial (Semple, Zamani, Rayner, Shultz \& Jones, 2019) path of the epileptic child. If we refer to the causes that lead to the diagnosis of this disease, studies of the last two decades acknowledge that causes are multifactorial such as the type of epilepsy (Kalaria, Akinyemi \& Ihara, 2016), the etiology of its outbreak (Lenck-Santini \& Scott, 2015), the age of onset (Korthauer, Awe, Frahmand \& Driscoll, 2018; Hamed, 2009), the frequency of seizures (Yoong, 2015), duration of the disease (Greaves, Psaltis, Ross, Davis \& Smith et al., 2019) and its treatment (Holmes, 2016; Vinciguerra, Graziano, Hagnäs, Frittitta \& Tumminia, 2020). In their research Kim and Ko (2016) acknowledges that cognitive impairments will depend on the link between pre-existing cognitive concerns in children before the onset of the crisis and the structural-functional changes in the brain (MRI) during the onset of the disease. It is precisely this common neurobiological

mechanism (Pardo, Nabbout \& Galanopoulou, 2014) that connects epilepsy with cognitive 
comorbidity. Referring to the findings investigating the link between IQ and epilepsy, it is revealed that low intelligence is related to the type of deficit and the frequency of epileptic seizures (Ping, Qin, Liu, Lu \& Zhao et al., 2019). So, children with a long history of epileptic seizures and with an active epilepsy, are considered a vulnerable group to cognitive issues, intelligence compromise and behavioral problems (Crudgington, Rogers, Morris, Gringras, Pal \& Morris, 2020). Children with a severe neurological deficit tend to show compromised levels of intelligence. However, referring to the influence of risk factors in the progression of the disease and into of cognitive issues, the relationship in not all clearly defined by field studies. Based on the different results, the relationship between epilepsy and risk factors should be seen from the context of the impact of dysfunction on a wider range and under the influence of the severity of epileptic seizures.

\section{Methods}

The sample of the current study $(\mathrm{N}=100)$ are school-age children between the 6-11 years old who receive treatment at the University Clinical Center of Kosovo, Department of Neurology and Pediatrics in Pristina, Kosovo. This sample is composed by $55 \%$ girls and $45 \%$ boys, from whom $14 \%$ attend first grade, $14 \%$ of attend the second grade, $26 \%$ are in the third grade, $18 \%$ in fourth grade, $18 \%$ in fifth grade and $10 \%$ of the children diagnosed with epilepsy are in the sixth grade. Medical data include demographic factors, duration of antiepileptic treatment (from 1 to more than 3 years), type of epileptic seizure (generalized, partial and mixed), electroencephalography (EEG of TEG 1.5), neuroimaging MRI) as well as the presence of comorbid neurological deficits have been reviewed retrospectively. Participants were assessed for the presence of cognitive impairments through the Montreal Cognitive Assessment scale (MoCA) to identify the presence of mild cognitive impairments such in the attention and concentration, executive functions, memory, speech/language, visual-spatial skills, abstractive thought, accounting and orientation. Fluid and crystallized intelligences was assessed with Raven's Standard Progressive Matrices (IQ), a nonverbal test for measuring the general IQ in children who have normal development in cognitive and motor functions, starting from lighter issues and gradually raising its difficulty. Behavioral issues were measured through the Child Behavior Checklist (CBCL) to identify behavioral issues in children. The school version (CBCL) is designed for children ages 6 to 18 years old. The answers are evidenced in Likert scale: $0=$ Not true, $1=$ Somehow or sometimes true, 2 = Very often or often true. It consists of 120 questions. Five participants were excluded as a result of serious cognitive impairments. All parents signed an informed consent contract to give the consent of their children to participate in the study.

\section{Statistical analyses}

Statistical analyzes were performed through the SPSS statistical program, version 20.0. Data are presented as the mean of the standard deviation or as percentiles (\%). Continuous variables were compared with the $T$ test or variance analysis (ANOVA) and discrete data with the x2 test. Correlations were tested with Pearson coefficients. Significant difference will be defined as $\mathrm{p}<0.05$. Since all research variables were three-level (e.g., the type of panic attack: generalized, 2. partial, mixed), then ANOVA was used. It enabled the comparison of the averages for each group and for checking the correlations between the variables of this research and to reconfirm the findings.

\section{Results}

Results reveal a statistically significant relationship between the frequency level of global cognitive development and the global IQ. The statistical significance (Sig.2-tailed) value for 
the level of cognitive development (MoCA) and coefficient level of intelligence (IQ) <0.05, the relationship between the level of cognitive development associated with the IQ is not random, but statistically significant. "Pearson" ( $r=.300$ for cognitive development) is: Sig (2 Tailed) $\mathrm{p}=0.01$ $<0.05$. First, this value is positive, which means that there is a positive correlation between variables (cognitive development and IQ). So, there is a statistically significant relationship between the level of cognitive development and the IQ.

As the level of cognitive development in children with epilepsy increases, so does their IQ. The more cognitive problems children with epilepsy have, the lower their IQ. The fewer cognitive problems children have, the higher the level of cognitive development, the higher the level of IQ. Based on the correlational analysis there is an important statistical relationship between the frequency of the global scale of behavioral problems and the global scale of the IQ. The value of statistical significance Sig. ( 2 tailed) $\mathrm{p}=0.01<0.05$, the relationship between behavioral problems (CBCL) and IQ is statistically significant, $r=0.661$, so the relationship between the two variables is strong and positive as values for behavioral problems increase, so do the values for the IQ of children. In conclusion, there is a significant statistical relationship between the lack of problems in the behavior of children with epilepsy and the average frequency of their IQ. As values increase for lack of behavioral issues, their IQ increases and this is a strong statistical relationship.

Table 1. Correlation between cognitive problems (MoCA) and the total mean of the Intellectual Coefficient (IQ) and behavioral problems (CBCL)

\begin{tabular}{lllll}
\hline & & Moca & IQ & CBCL \\
\hline Total & Moca & & \\
& IQ & - & - & \\
& CBCL & $.300^{* *}$ & $.661^{* *}$ & - \\
\hline ** Correlation is significant at the o.01 level (2-tailed). &
\end{tabular}

**. Correlation is significant at the o.o1 level (2-tailed).

The relationship between cognitive development and IQ in children with epilepsy Sig. ( 2 tailed) $\mathrm{p}=0.01<0.05, \mathrm{r}=.300$ is positive and moderate. The higher the cognitive development of children with epilepsy, the higher the level of their IQ. While the relationship between behavioral problems and IQ in children with epilepsy is Sig. ( 2 tailed) $p=0.01<0.05, r=.661$, the relationship is positive and strong. The higher the level of lack of behavioral problems, the higher the level of intelligence of children with epilepsy. It results that the relationship between the duration of therapeutic treatment and the type of attack (Sig. ( 2 tailed) $p=0.01<0.05, r=.284$ ) is positive and moderate. The greater the duration over the years in therapeutic treatment within health and rehabilitation centers for children with epilepsy, the more noted will be the type of epileptic seizure. The relationship between neurological deficit type and cognitive development (MoCA) (Sig. (2 tailed) p = $0.01<0.05, r=-.469$ ) is negative and of moderate severity. The more severe the type of neurological deficit, the more issues will emerge in the cognitive development of children with epilepsy. The relationship between neurological deficit type and IQ (Sig. (2 tailed) $\mathrm{p}=0.01<0.05, \mathrm{r}=-.666)$ is negative and strong. The more severe the type of neurological deficit in children with epilepsy, the lower the IQ. The relationship between neurological deficit type and behavioral issues (CBCL) (Sig. ( 2 tailed) $\mathrm{p}=0.01<0.05, \mathrm{r}=-.461$ ) is negative and of moderate severity. The more severe the type of neurological deficit, the lower the score for behavioral issues in children with epilepsy. The relationship between EEG registration values and the type of epileptic seizure (Sig. ( 2 tailed) $\mathrm{p}=0.01<0.05, \mathrm{r}=.835$ ) is positive and of significant strength. The lighter the EEG values recorded in children with epilepsy, the easier the type of epileptic seizure will be. The relationship between EEG records values and duration of treatment (Sig. (2 
tailed) $\mathrm{p}=0.01<0.05, \mathrm{r}=.366$ ) is positive and of moderate severity. The higher the values recorded in the EEG in children with epilepsy, the longer the duration of treatment with therapy. The relationship between structural changes in MRI and cognitive development (Sig. ( 2 tailed) p $=0.01<0.05, \mathrm{r}=-.472$ ) is negative and of moderate severity. The greater the structural changes in MRI in children with epilepsy, the lower their cognitive development. The relationship between structural changes in MRI and IQ (Sig. ( 2 tailed) $p=0.01<0.05, r=-.560$ ) is statistically negative and strong.

The greater the structural changes in MRI in children with epilepsy, the lower their IQ. The relationship between structural changes in MRI and behavioral problems (CBCL) (Sig. (2 tailed) $\mathrm{p}=0.01<0.05, \mathrm{r}=-.454$ ) is negative and of moderate severity. The greater the structural changes in MRI in children with epilepsy, the lower the behavioral issues. The relationship between structural changes in MRI and the type of neurological deficit (Sig. (2 tailed) p $=0.01$ $<0.05 \mathrm{r}=.860$ ) is positive and stronger. The greater the structural changes in MRI in children with epilepsy, the more severe the type of neurological deficit that appears in them. The relationship between the number of epileptic seizures and the type of epileptic seizure (Sig. (2 tailed) $\mathrm{p}=0.01<0.05, \mathrm{r}=.884$ ) is positive and fairly strong. The greater the number of epileptic seizures in children with epilepsy, the more severe the type of epileptic seizure that associates this disorder.

The relationship between the number of epileptic seizures and the duration of treatment (Sig. ( 2 tailed) $\mathrm{p}=0.05<0.05, \mathrm{r}=.255$ ) is positive and weak. The greater the number of epileptic seizures in children with epilepsy, the longer the duration of therapy followed by them. The relationship between the number of epileptic seizures and the record value in EEG (Sig. (2 tailed) $\mathrm{p}=0.01<0.05, \mathrm{r}=.860$ ) is positive and quite strong. The higher the number of epileptic seizures in children with epilepsy, the higher the EEG recorded values.

Table 2. Correlation graphs of the MoCA, IQ, CBCL global scales and the type of epileptic attack, duration of treatment, neurologic deficit, EEG records, structural changes in MRI and the quantity of epileptic attacks in children with epilepsy $(\mathrm{N}=100)$

\begin{tabular}{|c|c|c|c|c|c|c|c|c|c|}
\hline & $\mathbf{1}$ & 2 & 3 & 4 & 5 & 6 & 7 & 8 & 9 \\
\hline 1. Moca Total & - & & & & & & & & \\
\hline 2. IQ & $.300^{* * *}$ & - & & & & & & & \\
\hline 3. CBCL & .192 & $.661^{* * *}$ & - & & & & & & \\
\hline $\begin{array}{l}\text { 4. Type of epileptic } \\
\text { attack }\end{array}$ & -.158 & -.080 & -.074 & - & & & & & \\
\hline 5. Duration of treatment & .007 & -.087 & -.053 & $.284^{* *}$ & - & & & & \\
\hline 6. Neurologic Deficit & $-.469^{* * *}$ & $-.666^{* *}$ & $-.461^{* *}$ & .190 & .167 & - & & & \\
\hline 7. EEG recording & -.111 & -.066 & -.066 & $.835^{* *}$ & $.366^{* *}$ & .023 & - & & \\
\hline $\begin{array}{l}\text { 8. Structural changes in } \\
\text { MRI }\end{array}$ & $-.472^{* *}$ & $-.560^{* *}$ & $-.454^{* * *}$ & $.209^{*}$ & .068 & $.860^{* *}$ & .030 & - & \\
\hline $\begin{array}{l}\text { 9. Number of epileptic } \\
\text { attacks }\end{array}$ & -.161 & -.167 & -.132 & $.884^{* *}$ & $.255^{*}$ & .174 & $.833^{* * *}$ & .150 & - \\
\hline
\end{tabular}

**. Correlation is significant at the o.o1 level (2-tailed).

*. Correlation is significant at the o.o5 level (2-tailed). 


\section{Discussion}

Based on the results of the duration of drug treatment, findings show that most children have a long period of follow-up in therapy for more than 3 years at the Center for Pediatric Neurology and at the "Hope" center. They are followed by the group of children who have a followup from 1 to 3 years and then, there is a small percentage of children who are treated for less than a year. Referring to the forms of therapy that are applied in these centers, there is a combination between treatment that aims at medical intervention through antiepileptics and the psychological intervention (Crudgington, Rogers, Morris, Gringras \& Pal et al., 2020) through neurodevelopmental therapy for children with epilepsy who have compromised this aspect of their functioning. Regardless of the type of neurodevelopmental impairment and therapeutic intervention taken by patients with epilepsy, an ongoing assessment process is performed for all children who have been diagnosed and followed up at these centers. Based on the timely scope of treatment, referring also to the findings from other studies, there are contradictory data that medicalor psychological treatment (French Intensive Care Society International Congress, 2020) have on the prognosis of children in the long-term perspective (Bulaj, Ahern, Kuhn, Judkins \& Bowen et al., 2016). Groups of researchers have acknowledged that new antiepileptic drugs do not show clinical evidence on their efficacy in long-term use in the treatment of children with epilepsy. Research (Bulaj, Ahern, Kuhn, Judkins \& Bowen et al., 2016; Aliyu, Abdullahi, Iliyasu, Salihu \& Adamu et al., 2019) was conducted on the effects on the long-term plan based on numerous studies mainly in pediatric ages. They have concluded that the data are insufficient to balance the risk and benefits (Aliyu, Abdullahi, Iliyasu, Salihu \& Adamu et al., 2019) that the child has in the long term medical treatment or influenced by social factors such as the income available to the family and the state to support the structures with technology contemporary to make an adequate diagnosis of children. This finding should prompt us to reflect on the consequences of side effects associated with the use of antiepileptic drugs (Suraev, Lintzeris, Stuart, Kevin \& Blackburn et al., 2018; AicuaRapun, André \& Novy, 2019) to treat epilepsy for a long period of time and on the impact, it may have in terms of compromising in different areas along the normal course of development of the child (Dugger, Platt \& Goldstein, 2018). Referring to the conclusions of O'Brien and colleagues (O’Brien, Clapham, Krysiak, Batchelor \& Field et al., 2019) it is a necessity to consider the age factor to determine the dosage forms that must first be focused and give priority to the safety and acceptability of the child, which are consistent with his or her development and skills and to avoid the wrong treatment that comes from the development of inappropriate formulations. However, based on the results of the study participants, we have no evidence to show a negative impact of drug treatment for a long time in the field of behavior, issues with cognitive functioning or the presence of association of this variable with a low IQ. Mostly children with epilepsy who are treated with pharmacological therapy for more than 3 years do not have any association with other neurological damage and also did not show any implications for increasing the level of behavioral issues compared to the group of children receiving therapy for a shorter time. In terms of various aspects related to cognitive development and IQ, there is no connection between these two variables, i.e. the duration of follow-up with therapy and problems or their improvement compared to children receiving this treatment for a shorter time.

Referring to our findings, it is revealed that in the majority of children participating in the study, another neurological deficit with epilepsy disorder is not associated. This evidence allows us to predict that the prognosis of children who do not have another concomitant epilepsy impairment will be positive and will not be the cause for onset throughout the course of developmental problems in cognitive functioning, behavior and IQ. At low levels, the presence of a mild and moderate deficit appears.

These results give us the opportunity to argue that by referring to the severity of the symptoms shown in relation to the presence of other neurological impairments in children participating in the study, we will inevitably have problems with their cognitive development and 
IQ. Epileptic children without neurological deficits, who make up the largest number of participants, will inevitably present problems at serious levels in terms of attention, visual-spatial executive skills, short-term memory, spoken language, abstract thinking, etc. time and space orientation. This means that children meet all the conditions for normal development in terms of fulfilling their duties related to self-care, school, family and social interaction with peers and adults in normal developmental context. A small number of children diagnosed with epilepsy have an association by the presence of a mild and moderate deficiencies, which seem to have an impact on the field of cognitive and behavioral development of children, thus increasing the probability for a more complex prognosis which requires the follow of medical and psychological treatment as necessary. As a form that facilitates the global functioning of the child in all areas of life and increases the possibility of a normal course of formative itineraries related to tasks in the school context and personal development, early intervention is considered a strong element, but in this context, it is important to consider competent assessment of appropriate forms of drug intervention if necessary, considering the chronological age and cognitive development of the child. Based on the findings of other studies (Chang, Krishnan, Dulla, Jette \& Marsh et al., 2020) it is revealed that epilepsy is associated with a number of neuropsychiatric and somatic problems which have a major impact on the continuity of treatment. Chang and colleagues argue that the lack of a neurological deficit reduces the risks of appearing in the clinical view of epilepsy other complications such as problems in the child's cognitive and behavioral development. Recent technological developments have helped us better understand the causal role of genes responsible for various types of epilepsy (Coryell, Gaillard, Shellhaas, Grinspan \& Wirrell et al., 2018), but it is still unclear how their impact will determine the severity of symptoms from one individual to another. These data shall be considered by the medical staff in order to increase vigilance and extend the time required for a careful diagnosis and appropriate to symptomatology (Silvestro, Mammana, Cavalli, Bramanti \& Mazzon, 2019) and its typology to each patient. This approach combined with professional competence allows us to build a successful long-term intervention plan for all of our young patients diagnosed with epilepsy. An interesting finding that requires attention in this discussion is related to the number of antiepileptic drugs as the form through which these children are treated during the course of epilepsy disorder. The pharmacological treatment followed in our case demonstrates that all children participating in the study are treated with pharmacological therapy. Referring to the above evidence, it is revealed that a good part of these children is diagnosed with epilepsy but without neurological deficits (about $67 \%$ of children), compared to those who receive pharmacological treatment for more than 3 years (about $62 \%$ of children) and without changes in MRI (about $65 \%$ of children). We have a relatively large number of children who are treated with an antiepileptic medical (drug) or with two medications combined together. There were also children who take more than two medications to treat epileptic symptoms.

It is considered unclear, although outside our professional expertise, the increased number of drugs that these children are treated with. This finding is related to the abovementioned evidences which present us with a picture without obvious compromises referring to the severity of the symptoms and the lack of association of epilepsy with other neurological problems. This evidence that the study highlighted aims to draw attention to the encouragement of a reflection on the long-term consequences that taking these medications may have on the child's developmental process and the possible side effects of their prolonged use. Based on studies (Panebianco, Al-Bachari, Weston, Hutton \& Marson, 2018; Nevitt, Sudell, Weston, Tudur Smith \& Marson, 2017) on the effects of antiepileptic drugs, researchers agree that certain conditions related to administration of antiepileptic drugs to school-age children should be carefully considered. These conditions suggest a reduced number of medications at young ages and a careful evaluation of side effects and long-term impact on child development (de Bruijn, van Sonderen, van Coevorden-Hameete, Bastiaansen \& Schreurs et al., 2019). The use of medication should be considered necessary only for those children who are at a pronounced level of neurological 
impairment (Fleming, Fitton, Steiner, McLay \& Clark et al., 2019). Referring to the use of various research drugs (de Bruijn, van Sonderen, van Coevorden-Hameete, Bastiaansen \& Schreurs et al., 2019; Grinspan, Shellhaas, Coryell, Sullivan \& Wirrell et al., 2018; Kaushik, Chopra, Sharma \& Aneja, 2019), it's important to assess new and old medications in school ages based on the impact they may have on long-term perspective (McTague, Martland \& Appleton, 2018). Problems with internalizing and externalizing behaviors tend to increase in the group of children who have epileptic comorbidities with a moderate and severe deficit compared to the group of children without deficit or mild impaired. The presence of a moderate and severe neurological deficit appears to increase the difficulty of children in terms of overall functioning in the school, family and social context. This result is also accepted by research (Dabbs et al., 2013; Shinner et al., 2017; Munger et al., 2018) where rather the increase of behavioral problems is dedicated to the combination of several factors, among which the association of a neurological deficit has a negative impact on the child's life. So, we can imply that based on the so far evidence some of the antiepileptic drugs used to keep epileptic seizures under control seem to be associated with a higher risk than others (Boshuisen, Lamberink, van Schooneveld, Cross \& Arzimanoglou et al., 2015). Here it can be included clobazam, clonazepam, levetiracetam, perampanel, phenobarbital, tiagabine, topiramate, vigabatrina, and zonisamidena. The highest probability of developing aggressive behaviors should be explained to any patient who begins treatment with any of these medications, especially for those children who have had previous history of anger management issues (Berg, Zelko, Levy \& Testa, 2012). Among antiepileptic drugs, there is strong evidence of a risk of aggressive behavior for levetiracetam, perampanel and possibly topiramate, but most children taking these or other medications will not have problems with aggressive behaviors (Andresen, Ramirez, Kim, Dorfman \& Haut et al., 2014). Parental involvement in discussing the determination of selected drugs for the child is significant, as they recognize and can provide information on the temperament and previous aggressive behaviors of children with epilepsy. These issues should be considered when choosing pharmacological therapy for all patients with newly diagnosed or chronic epilepsy. Regarding the presence of internalizing and externalizing issues in the behavior of children with epilepsy, it seems that the factors that promote aggravation of problems in this area are related to the type of moderate or severe neurological deficit with structural changes recorded in MRI, which likely make it difficult for the child to progress in his $\backslash$ her developmental process and interfere in a number of important areas causing problems such as the child's performance in school and overall psychological well-being by encouraging the child to cope with anxiety, depression or anger management problems and aggression. But in terms of social functioning it seems that children who show the presence of a severe neurological deficit and marked structural changes in MRI will have a number of problems in relation to how they will build relationships with others significant to them, but also with others, with whom the child is obliged to interact in different contexts. It seems that in fact the severity of behavioral issues in children with epilepsy will depend on how the disease will find or not find the favorable path for progress or regression under the influence of a number of factors such as the severity of panic attacks, the duration of the attacks. Epileptic seizure, their quantity, neurological deficits and structural changes and damages in areas of the brain, the child's intelligence and behavioral problems are seen as predominant to the degree of problems and directly affect the cognitive aspects. The type of epileptic seizure appears to be strongly influenced by changes in the brain's electrical waves recorded on the EEG, the duration of treatment, structural changes in MRI and the number of epileptic seizures. Referring to studies (Kossoff, Zupec-Kania, Auvin, Ballaban-Gil \& Christina Bergqvist et al., 2018) it is also revealed that depending on the type of generalized epileptic seizure, associated with a longer duration of treatment with antiepileptics, it is worth noting that even the number of antiepileptics that the child takes has a negative impact on congenital and behavioral development if given for a very long time. Children with epilepsy tend to have a more aggravated picture of problems in terms of cognitive functioning, intelligence and behavioral problems if the epileptic seizure is generalized, mixed (partial/generalized) compared to the partial one. Epileptic children depending on the type of epileptic seizure attack will trigger 
the need for a therapeutic intervention which considers the presence of a generalized or mixed attack, the duration of treatment, the recording of electrical waves in the EEG and the number of epileptic attacks. These factors have a direct impact on how the child will cope with the disease and how it will adapt to the tasks and responsibilities related to his $\backslash$ her age.

In conclusion we can imply that based on the severity of these concomitant factors of the epileptic conditions, they will constitute a high-risk factor for cognitive problems, low intelligence and the emergence of a number of internalizing and externalizing problems of the child with epilepsy. The study also noted that the duration of treatment will be affected by the level of changes in the brain's electrical waves recorded on the EEG and the number of epileptic seizures, while the neurological deficit that associates epilepsy will depend on structural changes recorded on MRI. The changes in EEG-recorded waves will depend on the number of epileptic seizures. Referring to findings of the study which are also confirmed by other research (Zelko, Pardoe, Blackstone, Jackson \& Berg, 2014) we can acknowledge the superiority of biological factors over other psycho-social factors in determining the severity of symptoms of the occurrence of epilepsy in children.

\section{Conclusion}

In conclusion, we can refer that fact that the child is diagnosed with epilepsy whether it is an only one does not constitute a condition for having cognitive and behavioral problems in the long term. But a combination of several factors increases the risk of dealing with an epileptic child with a range of cognitive and behavioral issues that will severely impair the progress of his or her development and their quality of life in the overall view. Children diagnosed with epilepsy who have received insufficient and inappropriate education, with frequent epileptic seizures, generalized type seizures, with longer time duration, who have problems with depression, who have started treatment with antiepileptics very early and treated with more than one antiepileptic, summarize that all those significant factors that constitute favorable conditions for the development of congenital problems. Under the influence of a severe neurological deficit, marked changes in the electrical waves of the brain recorded on the EEG and with data on marked changes on MRI, accompanied by a number of frequent epileptic seizures, also constitute the path for clinical picture with aggravated symptoms in cognitive functions, with a deep compromise of the IQ and with aggravated levels of problems in the internalizing and externalizing behaviors of children with epilepsy. Risk factors related to the interaction of psychological and biological factors favor the ground for compromising the child's cognitive development and interfere in the course of the epileptic disease.

\section{Acknowledgements}

This research did not receive any specific grant from funding agencies in the public commercial, or not-for-profit sectors.

The authors declare no competing interests.

\section{References}

Abstracts from the $51^{\text {st }}$ European Society of Human Genetics Conference: Posters. (2019). European Journal of Human Genetics, 27(Suppl 1), 1-688. https://doi.org/10.1038/s41431-019-0404-7

Aicua-Rapun, I., André, P., \& Novy, J. (2019). Closed-loop neuropharmacology for epilepsy: Distant dream or future reality? Current Neuropharmacology, 17(5), 447-458.

https://doi.org/10.2174/1570159X16666180308154646 
Aliyu, M. H., Abdullahi, A. T., Iliyasu, Z., Salihu, A. S., Adamu, H., Sabo, U., Garcia, J. P., Abdullahi, S. U., Mande, A., Xian, H., Yakasai, H. M., Schootman, M., Ingles, D. J., Patel, A. A., Yakasai, A., Curry-Johnson, S., Wudil, U. J., DeBaun, M. R., Trevathan, E., \& BRIDGE Advisory Panel (2019). Bridging the childhood epilepsy treatment gap in northern Nigeria (BRIDGE): Rationale and design of pre-clinical trial studies. Contemporary Clinical Trials Communications, 15, 100362. https://doi.org/10.1016/j.conctc.2019.100362

Andresen, E. N., Ramirez, M. J., Kim, K. H., Dorfman, A. B., Haut, J. S., Klaas, P. A., Jehi, L. E., Shea, K., Bingaman, W. E., \& Busch, R. M. (2014). Effects of surgical side and site on mood and behavior outcome in children with pharmacoresistant epilepsy. Frontiers in Neurology, 5, 18. https://doi.org/10.3389/fneur.2014.00018

Berg, A. T., Zelko, F. A., Levy, S. R., \& Testa, F. M. (2012). Age at onset of epilepsy, pharmacoresistance, and cognitive outcomes: A prospective cohort study. Neurology, 79(13), 1384-1391. https://doi.org/10.1212/WNL.obo13e31826c1b55

Boshuisen, K., Lamberink, H. J., van Schooneveld, M. M., Cross, J. H., Arzimanoglou, A., van der Tweel, I., Geleijns, K., Uiterwaal, C. S., \& Braun, K. P. (2015). Cognitive consequences of early versus late antiepileptic drug withdrawal after pediatric epilepsy surgery, the TimeToStop (TTS) trial: study protocol for a randomized controlled trial. Trials, 16, 482. https://doi.org/10.1186/s13063-015-0989-2

Brooks-Kayal, A. R., Bath, K. G., Berg, A. T., Galanopoulou, A. S., Holmes, G. L., Jensen, F. E., Kanner, A. M., O'Brien, T. J., Whittemore, V. H., Winawer, M. R., Patel, M., \& Scharfman, H. E. (2013). Issues related to symptomatic and disease-modifying treatments affecting cognitive and neuropsychiatric comorbidities of epilepsy. Epilepsia, 54 Suppl 4(o 4), 44-60. https://doi.org/10.1111/epi.12298

Bulaj, G., Ahern, M. M., Kuhn, A., Judkins, Z. S., Bowen, R. C., \& Chen, Y. (2016). Incorporating natural products, pharmaceutical drugs, self-care and digital/mobile health technologies into molecular-behavioral combination therapies for chronic diseases. Current Clinical Pharmacology, 11(2), 128-145. https://doi.org/10.2174/1574884711666160603012237

Burke, S. L., Naseh, M., Rodriguez, M. J., Burgess, A., \& Loewenstein, D. (2019). Dementia-related neuropsychological testing considerations in non-Hispanic white and Latino/Hispanic populations. Psychology \& Neuroscience, 12(2), 144-168.

https://doi.org/10.1037/pneo000163

Cacabelos R. (2020). Pharmacogenomics of cognitive dysfunction and neuropsychiatric disorders in dementia. International Journal of Molecular Sciences, 21(9), 3059. https://doi.org/10.3390/ijms21093059

Chang, B. S., Krishnan, V., Dulla, C. G., Jette, N., Marsh, E. D., Dacks, P. A., Whittemore, V., Poduri, A., \& NINDS/AES Epilepsy Research Benchmark Stewards Committee (2020). Epilepsy benchmarks area I: Understanding the causes of the epilepsies and epilepsy-related neurologic, psychiatric, and somatic conditions. Epilepsy Currents, 20(1_suppl), 5S-13S. https://doi.org/10.1177/1535759719895280, E. D., Dacks, P. A., Whittemore, V., Poduri, A., \& NINDS/AES Epilepsy Research Benchmark Stewards.

Coryell, J., Gaillard, W. D., Shellhaas, R. A., Grinspan, Z. M., Wirrell, E. C., Knupp, K. G., Wusthoff, C. J., Keator, C., Sullivan, J. E., Loddenkemper, T., Patel, A., Chu, C. J., Massey, S., Novotny, E. J., Jr, Saneto, R. P., \& Berg, A. T. (2018). Neuroimaging of early life epilepsy. Pediatrics, 142(3), e20180672. https://doi.org/10.1542/peds.2018-0672

Crudgington, H., Rogers, M., Morris, H., Gringras, P., Pal, D. K., \& Morris, C. (2020). Epilepsy-specific patient-reported outcome measures of children's health-related quality of life: A systematic review of measurement properties. Epilepsia, 61(2), 230-248.

https://doi.org/10.1111/epi.16430

Dabbs, K., Jones, J. E., Jackson, D. C., Seidenberg, M., \& Hermann, B. P. (2013). Patterns of cortical thickness and the Child Behavior Checklist in childhood epilepsy. Epilepsy \& Behavior: $E \& B, 29(1), 198-204$. https://doi.org/10.1016/j.yebeh.2013.07.008 
de Bruijn, M., van Sonderen, A., van Coevorden-Hameete, M. H., Bastiaansen, A., Schreurs, M., Rouhl, R., van Donselaar, C. A., Majoie, M., Neuteboom, R. F., Sillevis Smitt, P., Thijs, R. D., \& Titulaer, M. J. (2019). Evaluation of seizure treatment in anti-LGI1, anti-NMDAR, and anti-GABA $A_{B} R$ encephalitis. Neurology, 92(19), e2185-e2196.

https://doi.org/10.1212/WNL.0000000000007475

de Bruijn, M., van Sonderen, A., van Coevorden-Hameete, M. H., Bastiaansen, A., Schreurs, M., Rouhl, R., van Donselaar, C. A., Majoie, M., Neuteboom, R. F., Sillevis Smitt, P., Thijs, R. D., \& Titulaer, M. J. (2019). Evaluation of seizure treatment in anti-LGI1, anti-NMDAR, and anti-GABAB R encephalitis. Neurology, 92(19), e2185-e2196. https://doi.org/10.1212/WNL.0000000000007475

Dugger, S. A., Platt, A., \& Goldstein, D. B. (2018). Drug development in the era of precision medicine. Nature reviews. Drug discovery, $17(3), 183-196$. https://doi.org/10.1038/nrd.2017.226

E-Poster Viewing. (2019). European Stroke Journal, 4(1 Suppl), 150-276. https://doi.org/10.1177/2396987319845581

Fleming, M., Fitton, C. A., Steiner, M., McLay, J. S., Clark, D., King, A., Mackay, D. F., \& Pell, J. P. (2019). Educational and health outcomes of children and adolescents receiving antiepileptic medication: Scotland-wide record linkage study of 766,244 schoolchildren. BMC Public Health, 19(1), 595. https://doi.org/10.1186/s12889-019-6888

Galanopoulou, A. S., \& Moshé, S. L. (2015). Pathogenesis and new candidate treatments for infantile spasms and early life epileptic encephalopathies: A view from preclinical studies. Neurobiology of Disease, 79, 135-149. https://doi.org/10.1016/j.nbd.2015.04.015

Greaves, D., Psaltis, P. J., Ross, T. J., Davis, D., Smith, A. E., Boord, M. S., \& Keage, H. (2019). Cognitive outcomes following coronary artery bypass grafting: A systematic review and meta-analysis of 91,829 patients. International Journal of Cardiology, 289, 43-49. https://doi.org/10.1016/j.ijcard.2019.04.065

Greenberg, D. A., \& Subaran, R. (2011). Blinders, phenotype, and fashionable genetic analysis: A critical examination of the current state of epilepsy genetic studies. Epilepsia, 52(1), 1-9. https://doi.org/10.1111/j.1528-1167.2010.02734.x

Grinspan, Z. M., Shellhaas, R. A., Coryell, J., Sullivan, J. E., Wirrell, E. C., Mytinger, J. R., Gaillard, W. D., Kossoff, E. H., Valencia, I., Knupp, K. G., Wusthoff, C., Keator, C., Ryan, N., Loddenkemper, T., Chu, C. J., Novotny, E. J., Jr, Millichap, J., \& Berg, A. T. (2018). Comparative effectiveness of levetiracetam vs phenobarbital for infantile epilepsy. JAMA Pediatrics, 172(4), 352-360. https://doi.org/10.1001/jamapediatrics.2017.5211

Hamed S. A. (2009). The aspects and mechanisms of cognitive alterations in epilepsy: The role of antiepileptic medications. CNS Neuroscience \& Therapeutics, 15(2), 134-156. https://doi.org/10.1111/j.1755-5949.2008.00062.x

Hermann, B., Loring, D. W., \& Wilson, S. (2017). Paradigm shifts in the neuropsychology of epilepsy. Journal of the International Neuropsychological Society: JINS, 23(9-10), 791-805. https://doi.org/10.1017/S1355617717000650

Hessen, E., Alfstad, K. Å., Torgersen, H., \& Lossius, M. I. (2018). Tested and reported executive problems in children and youth epilepsy. Brain and Behavior, 8(5), e00971. https://doi.org/10.1002/brb3.971

Hirosawa, T., Kikuchi, M., Fukai, M., Hino, S., Kitamura, T., An, K. M., Sowman, P., Takahashi, T., Yoshimura, Y., Miyagishi, Y., \& Minabe, Y. (2018). Association between magnetoencephalographic interictal epileptiform discharge and cognitive function in young children with typical development and with autism spectrum disorders. Frontiers in Psychiatry, 9, 568. https://doi.org/10.3389/fpsyt.2018.00568

Holmes G. L. (2014). What is more harmful, seizures or epileptic EEG abnormalities? Is there any clinical data? Epileptic Disorders: International Epilepsy Journal with Videotape, 16 Spec No 1(Spec No 1), S12-S22. https://doi.org/10.1684/epd.2014.0686 
Holmes G. L. (2016). Effect of seizures on the developing brain and cognition. Seminars in Pediatric Neurology, 23(2), 120-126. https://doi.org/10.1016/j.spen.2016.05.001

Izadi, A., Ondek, K., Schedlbauer, A., Keselman, I., Shahlaie, K., \& Gurkoff, G. (2018). Clinically indicated electrical stimulation strategies to treat patients with medically refractory epilepsy. Epilepsia Open, 3(Suppl Suppl 2), 198-209. https://doi.org/10.1002/epi4.12276

Jacobs, C. S., Willment, K. C., \& Sarkis, R. A. (2019). Non-invasive cognitive enhancement in epilepsy. Frontiers in Neurology, 10, 167. https://doi.org/10.3389/fneur.2019.00167

Jones, J. E., Asato, M. R., Brown, M. G., Doss, J. L., Felton, E. A., Kearney, J. A., Talos, D., Dacks, P. A., Whittemore, V., Poduri, A., \& NINDS/AES Benchmarks Stewards Committee (2020). Epilepsy benchmarks area IV: Limit or prevent adverse consequence of seizures and their treatment across the life span. Epilepsy Currents, 20(1_suppl), 31S-39S. https://doi.org/10.1177/1535759719895277

Kalaria, R. N., Akinyemi, R., \& Ihara, M. (2016). Stroke injury, cognitive impairment and vascular dementia. Biochimica et biophysica acta, 1862(5), 915-925. https://doi.org/10.1016/j.bbadis.2016.01.015

Kaushik, S., Chopra, D., Sharma, S., \& Aneja, S. (2019). Adverse drug reactions of anti-epileptic drugs in children with epilepsy: A cross-sectional study. Current Drug Safety, 14(3), 217-224. https://doi.org/10.2174/1574886314666190311112710

Kim, E. H., \& Ko, T. S. (2016). Cognitive impairment in childhood onset epilepsy: Up-to-date information about its causes. Korean Journal of Pediatrics, 59(4), 155-164. https://doi.org/10.3345/kjp.2016.59.4.155

Korthauer, L. E., Awe, E., Frahmand, M., \& Driscoll, I. (2018). Genetic risk for age-related cognitive impairment does not predict cognitive performance in middle age. Journal of Alzheimer's Disease: JAD, 64(2), 459-471. https://doi.org/10.3233/JAD-171043

Kossoff, E. H., Zupec-Kania, B. A., Auvin, S., Ballaban-Gil, K. R., Christina Bergqvist, A. G., Blackford, R., Buchhalter, J. R., Caraballo, R. H., Cross, J. H., Dahlin, M. G., Donner, E. J., Guzel, O., Jehle, R. S., Klepper, J., Kang, H. C., Lambrechts, D. A., Liu, Y., Nathan, J. K., Nordli, D. R., Jr, Pfeifer, H. H., ... Practice Committee of the Child Neurology Society (2018). Optimal clinical management of children receiving dietary therapies for epilepsy: Updated recommendations of the International Ketogenic Diet Study Group. Epilepsia Open, 3(2), 175-192. https://doi.org/10.1002/epi4.12225

Kynast, J., Lampe, L., Luck, T., Frisch, S., Arelin, K., Hoffmann, K. T., Loeffler, M., Riedel-Heller, S. G., Villringer, A., \& Schroeter, M. L. (2018). White matter hyperintensities associated with small vessel disease impair social cognition beside attention and memory. Journal of Cerebral Blood Flow and Metabolism: Official Journal of the International Society of Cerebral Blood Flow and Metabolism, 38(6), 996-1009. https://doi.org/10.1177/0271678X17719380

Lenck-Santini, P. P., \& Scott, R. C. (2015). Mechanisms Responsible for Cognitive Impairment in Epilepsy. Cold Spring Harbor Perspectives in Medicine, 5(10), a022772. https://doi.org/10.1101/cshperspect.a022772

Makale, M. T., McDonald, C. R., Hattangadi-Gluth, J. A., \& Kesari, S. (2017). Mechanisms of radiotherapyassociated cognitive disability in patients with brain tumors. Nature Reviews. Neurology, 13(1), 52-64. https://doi.org/10.1038/nrneurol.2016.185

McTague, A., Martland, T., \& Appleton, R. (2018). Drug management for acute tonic-clonic convulsions including convulsive status epilepticus in children. The Cochrane Database of Systematic Reviews, 1(1), CD001905. https://doi.org/10.1002/14651858.CD001905.pub3

Mollon, J., Mathias, S. R., Knowles, E., Rodrigue, A., Koenis, M., Pearlson, G. D., Reichenberg, A., Barrett, J., Denbow, D., Aberizk, K., Zatony, M., Poldrack, R. A., Blangero, J., \& Glahn, D. C. (2020). Cognitive impairment from early to middle adulthood in patients with affective and nonaffective psychotic disorders. Psychological Medicine, 5o(1), 48-57. https://doi.org/10.1017/So033291718003938 
Munger Clary, H. M., Snively, B. M., \& Hamberger, M. J. (2018). Anxiety is common and independently associated with clinical features of epilepsy. Epilepsy \& Behavior: E\&B, 85, 64-71. https://doi.org/10.1016/j.yebeh.2018.05.024

Nevitt, S. J., Sudell, M., Weston, J., Tudur Smith, C., \& Marson, A. G. (2017). Antiepileptic drug monotherapy for epilepsy: A network meta-analysis of individual participant data. The Cochrane Database of Systematic Reviews, 12(12), CDo11412. https://doi.org/10.1002/14651858.CD011412.pub3

Noebels J. L. (2015). Single-gene determinants of epilepsy comorbidity. Cold Spring Harbor Perspectives in Medicine, 5(11), a022756. https://doi.org/10.1101/cshperspect.a022756

O’Brien, F., Clapham, D., Krysiak, K., Batchelor, H., Field, P., Caivano, G., Pertile, M., Nunn, A., \& Tuleu, C. (2019). Making medicines baby size: The challenges in bridging the formulation gap in neonatal medicine. International Journal of Molecular Sciences, 20(11), 2688. https://doi.org/10.3390/ijms20112688

Panebianco, M., Al-Bachari, S., Weston, J., Hutton, J. L., \& Marson, A. G. (2018). Gabapentin add-on treatment for drug-resistant focal epilepsy. The Cochrane Database of Systematic Reviews, 1O(10), CDo01415. https://doi.org/10.1002/14651858.CDo01415.pub3

Pardo, C. A., Nabbout, R., \& Galanopoulou, A. S. (2014). Mechanisms of epileptogenesis in pediatric epileptic syndromes: Rasmussen encephalitis, infantile spasms, and febrile infection-related epilepsy syndrome (FIRES). Neurotherapeutics: The Journal of the American Society for Experimental Neurotherapeutics, 11(2), 297-310. https://doi.org/10.1007/s13311-014-02652.

Parrish, J. B, \& Fields, E. (2019). Cognitive functioning in patients with pediatric-onset multiple sclerosis, an updated review and future focus. Children (Basel, Switzerland) vol. 6, 2 21. 4 Feb. 2019, https://doi.org/10.3390/children6020021

Paudel, Y. N., Shaikh, M. F., Chakraborti, A., Kumari, Y., Aledo-Serrano, Á., Aleksovska, K., Alvim, M., \& Othman, I. (2018). HMGB1: A common biomarker and potential target for TBI, neuroinflammation, epilepsy, and cognitive dysfunction. Frontiers in Neuroscience, 12, 628. https://doi.org/10.3389/fnins.2018.00628

Perry, W., Lacritz, L., Roebuck-Spencer, T., Silver, C., Denney, R. L., Meyers, J., McConnel, C. E., Pliskin, N., Adler, D., Alban, C., Bondi, M., Braun, M., Cagigas, X., Daven, M., Drozdick, L., Foster, N. L., Hwang, U., Ivey, L., Iverson, G., Kramer, J., ... Golden, T. (2018). Population health solutions for assessing cognitive impairment in geriatric patients. Archives of Clinical Neuropsychology: The Official Journal of the National Academy of Neuropsychologists, 33(6), 655-675. https://doi.org/10.1093/arclin/acyo52

Ping, X., Qin, S. K., Liu, S. N., Lu, Y., Zhao, Y. N., Cao, Y. F., Zhang, Y. H., Zhang, S. D., Chu, L., \& Pei, L. (2019). Effects of Huazhuo Jiedu Shugan decoction on cognitive and emotional disorders in a rat model of epilepsy: Possible involvement of AC-cAMP-CREB signaling and NPY expression. Evidence-Based Complementary and Alternative Medicine: eCAM, 2019, 4352879. https://doi.org/10.1155/2019/43.52879

Proceedings of Réanimation 2020, the French Intensive Care Society International Congress. (2020). Annals of Intensive Care, 10 (Suppl 1), 16. https://doi.org/10.1186/s13613-020-06237

Ravizza, T., Onat, F. Y., Brooks-Kayal, A. R., Depaulis, A., Galanopoulou, A. S., Mazarati, A., Numis, A. L., Sankar, R., \& Friedman, A. (2017). WONOEP appraisal: Biomarkers of epilepsy-associated comorbidities. Epilepsia, 58(3), 331-342. https://doi.org/10.1111/epi.13652

Reddy, S. D., Younus, I., Sridhar, V., \& Reddy, D. S. (2019). Neuroimaging biomarkers of experimental epileptogenesis and refractory epilepsy. International Journal of Molecular Sciences, 2O(1), 220. https://doi.org/10.3390/ijms20010220 
Reilly, C., Atkinson, P., Memon, A., Jones, C., Dabydeen, L., Cross, J. H., Das, K. B., Gillberg, C., Neville, B., \& Scott, R. C. (2018). Child and parental sleep in young children with epilepsy: A populationbased case-control study. Epilepsia Open, 3(3), 383-391. https://doi.org/10.1002/epi4.12241

Semple, B. D., Zamani, A., Rayner, G., Shultz, S. R., \& Jones, N. C. (2019). Affective, neurocognitive and psychosocial disorders associated with traumatic brain injury and post-traumatic epilepsy. Neurobiology of Disease, 123, 27-41. https://doi.org/10.1016/j.nbd.2018.07.018

Shinnar, R. C., Shinnar, S., Cnaan, A., Clark, P., Dlugos, D., Hirtz, D. G., Hu, F., Liu, C., Masur, D., Weiss, E. F., Glauser, T. A., \& Childhood Absence Epilepsy Study Group (2017). Pretreatment behavior and subsequent medication effects in childhood absence epilepsy. Neurology, 89(16), 16981706. https://doi.org/10.1212/WNL.0000000000004514

Silvestro, S., Mammana, S., Cavalli, E., Bramanti, P., \& Mazzon, E. (2019). Use of cannabidiol in the treatment of epilepsy: Efficacy and security in clinical trials. Molecules (Basel, Switzerland), 24(8), 1459. https://doi.org/10.3390/molecules24081459

Suraev, A., Lintzeris, N., Stuart, J., Kevin, R. C., Blackburn, R., Richards, E., Arnold, J. C., Ireland, C., Todd, L., Allsop, D. J., \& McGregor, I. S. (2018). Composition and use of cannabis extracts for childhood epilepsy in the Australian community. Scientific Reports, 8(1), 10154. https://doi.org/10.1038/s41598-018-28127-O

Vinciguerra, F., Graziano, M., Hagnäs, M., Frittitta, L., \& Tumminia, A. (2020). Influence of the Mediterranean and ketogenic diets on cognitive status and decline: A narrative review. Nutrients, 12(4), 1019. https://doi.org/10.3390/nu12041019

Wang, L., Chen, S., Liu, C., Lin, W., \& Huang, H. (2020). Factors for cognitive impairment in adult epileptic patients. Brain and Behavior, 1O(1), e01475. https://doi.org/10.1002/brb3.1475

Wang, T. S., Liu, Q. Z., Liu, M., Zhang, Q., Wang, R. F., Wu, C. W., Zhang, J., Wang, W., Ji, T. Y., Liu, X. Y., Wang, S., Cai, L. X., Jiang, Y. W., \& Wu, Y. (2020). Clinical features and surgical outcomes in young children with focal cortical dysplasia type II. CNS Neuroscience \& Therapeutics, 26(2), 270-277. https://doi.org/10.1111/cns.13205

Williams, C. (2020). Reducing the burden of childhood cerebral visual impairment: another step forward. Developmental Medicine and Child Neurology, 62(1), 15. https://doi.org/10.1111/dmcn.14323

Yoong, M. (2015). Quantifying the deficit-imaging neurobehavioural impairment in childhood epilepsy. Quantitative Imaging in Medicine and Surgery, 5(2), 225-237. https://doi.org/10.3978/j.issn.2223-4292.2015.01.06

Zelko, F. A., Pardoe, H. R., Blackstone, S. R., Jackson, G. D., \& Berg, A. T. (2014). Regional brain volumes and cognition in childhood epilepsy: Does size really matter? Epilepsy Research, 108(4), 692700. https://doi.org/10.1016/j.eplepsyres.2014.02.003

Zhou, L., Chen, P., Peng, Y., \& Ouyang, R. (2016). Role of oxidative stress in the neurocognitive dysfunction of obstructive sleep apnea syndrome. Oxidative Medicine and Cellular Longevity, 2016, 9626831. https://doi.org/10.1155/2016/9626831 